\title{
Productive Aging in the Social Work Profession: A Comparison of Licensed Workers 60 Years and Older with Their Younger Counterparts
}

\author{
Shulamith Lala Ashenberg Straussner ${ }^{1}$ (D) Evan Senreich ${ }^{2}$
}

Published online: 28 January 2020

○) Springer Science+Business Media, LLC, part of Springer Nature 2020

\begin{abstract}
This article reports the findings of an online survey in 13 U.S. states that compared the self-described demographics, wellness factors (mental health, physical health, and substance misuse), practice factors (fields of practice and work environment issues), and feelings about being a social worker (compassion satisfaction, workplace stress, being glad one chose social work and feeling valued as a professional in society) of 870 employed licensed social workers age 60 and older to 4076 licensed social workers under age 60 . The results indicate that the older social workers were more likely to be male and white, less likely to report mental health problems, and more likely to work exclusively in private practice. Although older workers reported more serious physical health problems, they rated their physical health more favorably than their younger counterparts. In both bivariate and multivariate analyses, the older social workers scored significantly higher in compassion satisfaction, being glad they chose social work as a career, and feeling valued as a professional in society. The older social workers scored lower in workplace stress at levels that were statistically significant in a bivariate analysis, but not in a multivariate analysis.
\end{abstract}

Keywords Licensed social workers · Older social workers · Aging $\cdot$ Mental health $\cdot$ Substance misuse $\cdot$ Physical health Compassion satisfaction $\cdot$ Workplace stress

\section{Introduction}

As the working population of the United States ages (Gonzales et al. 2015), it can be expected that a larger number of licensed social workers will remain employed beyond the age of 60 . Yet we know very little about social workers' productive aging or the personal and professional issues faced by them as they grow older. The purpose of this paper is to examine the demographic and background factors, selfdescribed behavioral and physical health problems, and workplace issues experienced by more than 800 employed

Shulamith Lala Ashenberg Straussner

sls1@nyu.edu

Evan Senreich

evan.senreich@lehman.cuny.edu

1 New York University, Silver School of Social Work, New York, USA

2 Lehman College, City University of New York, New York, USA licensed social workers aged 60 and over, and to determine if and how these variables differ from their younger colleagues. Many studies have indicated that social work practice, especially when workers routinely interact with clients experiencing trauma, can be very stressful emotionally and can lead to secondary traumatic stress, compassion fatigue, and burnout for the workers (e.g. Bride 2007; Caringi et al. 2017; Johnson et al. 2005; Pelon 2017). With this in mind, it is important to learn how older social workers, who have often been working in the field for many years, view the stresses as well as the value of their work in comparison to their younger colleagues. Such knowledge could then inform ways to support older social workers as they continue working. While there is some debate as to what defines the lower boundary of the "aging" population, the cutoff age agreed to by the United Nations (UN) and the World Health Organization (WHO) for "older or elderly persons" is 60 years and over (WHO 2018, p. 1). This is also the age set by the Older Americans Act (Butler 2010) and is the cutoff age used by the researchers in this study. 


\section{Literature Review}

The concept of productive aging was first introduced in 1983 by Robert Butler in an effort to highlight the contributions of older adults in the United States (Butler and Gleason 1985).

According to Hinterlong, Morrow-Howell and Sherraden (2001), the concept of productive aging developed as a response to ageism and challenges the belief that older adults are only consumers of resources instead of active contributors to society. They note that definitions of productive aging differ in scope with some solely focusing on activities with economic worth, while others incorporate a broader range of behaviors. As an example of a more economically-focused conceptualization of productive aging, Caro, Bass, and Chen (as cited in Bass and Caro 2001) stated that productive aging "refers to any activity by an older individual that contributes to producing goods and services, or develops the capacity to produce them (whether or not the individual is paid for this activity)" (p. 39). However, Kaye et al. (2003) advocate for a definition that not only focuses on activities such as paid and volunteer work, but also includes "behaviors that are inner directed, personally meaningful, and satisfying" (p. 203). A more recent definition by the Centers for Disease Control and Prevention (CDC) (2011) states that "productive aging is an approach that emphasizes the positive aspects of growing older" (p. 1). The CDC's approach to productive aging focuses on the importance of organizational strategies tailored to meet the changing needs of workers across the life-span. Among the attributes of CDC's approach to productive aging is a life-span perspective that "considers the patterns of change and transition that occur in different domains (e.g., biological/physical, cognitive, social) from the first day on the job to the last" (CDC 2011, p. 1).

According to Berkman et al. (2015), "there is growing evidence that employment itself actively yields both physical and mental health benefits" for older adults (pp. 45-46). They note that working into older age improves cognitive, social, and emotional functioning, as well as delaying the use of savings, pensions, and other benefits. However, these authors state that older workers can experience vocational challenges pertaining to physical strength and health issues, gaps in their ability to use technology, and commitment to work. Bouville et al. (2018) research in France found that older workers had higher absenteeism than younger workers, and identified factors that influenced this relationship. Hsu's (2019) study in Taiwan found that work conditions are an important determinant in workers' engagement at the workplace and their decision to continue working into later adulthood. Hsu also found that younger cohorts scored at higher levels of both interpersonal and workplace stress than the older-aged groups.

Studies have generally indicated that older workers exhibit greater job satisfaction than workers in other age groups (Besen et al. 2013). However, while some have found a positive linear relationship between age and work satisfaction (e.g. Ng and Feldman 2010), others have shown a curvilinear relationship between these variables, with younger and older workers demonstrating greater job satisfaction than midlife workers (e.g. Hochwarter et al. 2001). Zacher and Schmitt (2016) reviewed numerous studies regarding occupational wellbeing that have demonstrated ways in which age is a moderating variable for the effects of different work factors, and ways in which work factors are moderating variables for the effects of age. For example, Besen et al. (2013) found that in a sample of over 2000 U.S. workers, the positive relationships between job satisfaction and work autonomy, skill variety, and co-worker friendships declined as the age of employees increased.

Research regarding older social workers appears to be extremely limited. A review of existing literature found studies examining burnout among helping professionals, with findings indicating that burnout decreases with age and years of work experience (Steel et al. 2015). However, Schwartz et al. (2007) found that this relationship held only for those working in private practice, with no differences in burnout over the years for those working in public agencies. In addition, studies have examined compassion satisfaction (CS) as it relates to the age of social workers and other helping professionals (Howard et al. 2015; Kelly et al. 2015). CS has been defined as the positive feelings one obtains from being involved in the healing process of other individuals (Kulkarni et al. 2013). Research studies indicate that the older a helping professional is, the greater their level of CS (Sacco et al. 2015). Craig and Sprang (2010) found that among a sample of social workers and psychologists specializing in trauma work, age and number of years of work experience tended to result in lower rates of burnout and compassion fatigue, and higher rates of CS, while Lawson and Myers' (2011) study of professional counselors found that younger counselors had significantly lower CS scores. Kulkarni et al. (2013) also found that the number of years of experience in the field was positively correlated with CS. The previously mentioned study by Steel et al. (2015) on burnout among mental health professionals pointed to age (specifically chronological age, not work experience) as a buffer against depersonalization and cynicism. This suggests that age can be a protective factor in the workplace, particularly among clinicians working directly with clients. 


\section{Study Aims}

As noted above, there have already been a number of studies that have focused on how clinicians' increasing age (as a continuous variable) affects their levels of compassion satisfaction and their levels of workplace stress, including burnout and compassion fatigue. However, there appear to be no studies that have specifically focused on the experiences of older social workers in this regard. In order to begin filling this gap in the literature and give older social workers the attention they deserve, the researchers of this study decided to dichotomize age in the analysis, specifically comparing the attributes and experiences of older social workers (age 60 and over) with social workers under age 60 .

This exploratory cross-sectional study examined: (1) Demographic factors; (2) Wellness factors (including issues related to mental health, physical health, and substance misuse); (3) Practice factors (including fields of practice and work environment issues), and (4) Feelings about being a social worker (including compassion satisfaction, workplace stress, being glad one chose social work as a profession, and feeling valued as a professional in society). The study had three central aims:

1. To provide an overview of selected demographic factors, wellness factors, practice factors, and feelings about being a social worker for respondents 60 years of age and older as compared to those under age 60;

2. To determine whether there were differences in compassion satisfaction and workplace stress between the age cohorts when stratified according to gender, race, sexual orientation, presence of mental health problems, and presence of serious physical health problems;

3. After controlling for selected demographic, wellness, and practice factors in a multivariate analysis, to examine how age (age 60 and older vs. under age 60) affects respondents' compassion satisfaction, workplace stress, and whether or not respondents feel glad that they chose social work as a profession and feel valued as a professional in society.

\section{Methods}

\section{Sample}

During the second half of 2015, the researchers contacted the professional licensing boards of all 50 U.S. states in order to inquire about the availability of email addresses of licensed social workers. Licensing boards in 13 states responded affirmatively, and valid email addresses were obtained for 69,661 licensed social workers in those states. Half of these, 34,831 , were randomly selected to take part in a 75-item online survey asking about their perceptions and feelings regarding their physical health, mental health and substance use issues, their work satisfaction and workplace stress, their perceptions of their work environment, their feelings about being a social worker, and demographic information (including the respondents' age). The 13 states included in this study represent the four federal regions as recognized by the U.S. Census Bureau, including the Northeast (Connecticut, New Jersey, and Rhode Island), the South (Arkansas, Florida, Oklahoma, and West Virginia), the Midwest (Minnesota and Ohio), and the West (New Mexico, Oregon, Washington, and Wyoming). Usable data were obtained from 6112 licensed social workers (representing a response rate of $28 \%$ ). Five respondents were randomly selected to receive a $\$ 200$ Amazon gift card as an incentive. The study's procedures were approved by the institutional review boards of the two academic institutions represented by the researchers.

As the purpose of this study was to compare the experiences and demographic factors of licensed social workers age 60 and older (conforming with the United Nations and World Health Organization's definition of "older adults") with their counterparts younger than 60 , only the 5526 surveys in which participants responded to the question "What is your age?" could be utilized. Furthermore, since the researchers wished to investigate the responses of licensed social workers who were currently employed in the profession, 580 surveys of participants who reported that they were not currently working as a social worker were eliminated from the analyses. This reduced the sample size to 4946. More specifically, the experiences of 870 licensed social workers age 60 and older were compared to those of 4076 licensed social workers under the age of 60 .

\section{Measures}

The survey included 75 closed-ended and open-ended items regarding personal and work issues. Questions relevant to this article came from the following sections of the survey: (1) Behavioral and physical health issues; (2) Utilization of behavioral health services; (3) Professional background and work experiences; and (4) Demographic and personal information. (For a fuller description of the survey questions, see Senreich et al. (2019), and Straussner et al. (2018)).

The variables examined in this study were operationalized as follows: 


\section{Demographic Factors}

These included age, gender, race, immigration status, sexual orientation, religion, and marital status. Age was a dichotomous variable coded as (1) for age 60 and older and (0) for younger than 60. Gender was coded as (1) female, (2) male, and (3) non-binary. Race was coded as: (1) White, (2) Black/ African American, (3) Latino/Hispanic, (4) Asian (including East Asian, South Asian, Native Hawaiian and/Pacific Islander), and (5) Mixed/Other (including Middle Eastern, Native American, or respondents choosing multiple categories). Immigration status was coded as (1) born in the United States or (0) not born in the United States. Sexual orientation was coded as (1) heterosexual or (0) sexual minority (including bisexual, gay/lesbian, or "other"). Religion was coded as (1) Christian, (2) Jewish, (3) Buddhist, (4) Spiritual, but not Religious, (5) Agnostic/Atheist, (6) None, and (7) Other (includes Hindu, Muslim, another category, or respondents choosing multiple categories). Marital status was coded as (1) single, never married, (2) married or having a domestic partner, (3) divorced or separated, (4) widowed, or (5) other (including another category or respondents choosing multiple categories).

\section{Wellness Factors}

These included the current presence of mental health problems, serious physical health problems, substance misuse problems, tobacco use, as well as utilization in the prior year of outpatient mental health treatment and psychotropic medications. Respondents were also asked to rate their physical health. For the presence of mental health problems, serious physical health problems, and substance misuse problems, participants were asked if they "strongly agree"; "agree"; "disagree"; and "strongly disagree." Respondents were coded as having the problem (1) if they answered "strongly agree" or "agree," and were coded as not having the problem (0) if they answered "disagree" or "strongly disagree." Those who chose "strongly agree" or "agree" to having a mental health problem were then asked what type(s) of mental health problems they were experiencing and were given a choice of 13 different types of symptoms. Since "anxiety" and "depression" were by far the most frequent responses chosen, these are the only two symptoms analyzed in this study and coded as (1) having anxiety if they chose that symptom, or (0) if they did not indicate having that symptom. The same procedure was followed for coding depression. Participants were also asked about their utilization of mental health services in the past year. Those who reported using mental health services in the past 12 months were coded as (1), whereas the others were coded as (0). This coding procedure was repeated for use of psychotropic medication in the past year. Participants were also asked to rate their general health as "excellent," "very good," "good," "fair," and "poor." These responses were collapsed into three coding categories: (1) fair/poor, (2) good, and (3) excellent/ very good. Last, respondents were asked about their tobacco use and responses were coded as (1) currently using tobacco and $(0)$ currently not using tobacco.

\section{Practice Factors}

Respondents were asked about their highest social work degree, their area of practice, whether they work exclusively in private practice, and their total number of years of social work practice. Highest degree was coded as (1) BSW, (2) MSW, and (3) doctoral degree. Area of practice was coded as (1) direct practice only, (2) indirect practice only, and (3) both direct and indirect practice. Working exclusively in private practice was coded as (1), and (0) if this was not the case. Participants were asked to fill in their number of years of practice as a social worker.

\section{Fields of Practice}

Based on National Association of Social Workers (NASW) categorization, participants were presented with 21 fields of practice and were asked to choose the ones in which they had worked primarily throughout their social work career. They were instructed to pick as many fields as apply. These were coded as (1) Aging/Older adults, (2) Child welfare, (3) Children/Adolescents, (4) Criminal justice/Legal, (5) Developmental/Intellectual disabilities, (6) Disaster response, (7) Employee assistance programs, (8) Families/Couples, (9) Health/Medical, (10) Housing/Homelessness, (11) Hospice/Palliative care, (12) Immigration/Refugees, (13) International, (14) Mental Health, (15) Military/Veterans, (16) Physical disabilities, (17) Public service/Government, (18) Schools, (19) Substance abuse, (20) Unemployment, and (21) Welfare/Public benefits. Participants could also add fields of practice not covered by this list. However, none of the additional fields reached a substantial number and were therefore not analyzed.

\section{Compassion Satisfaction}

The survey included the 10-item Compassion Satisfaction subscale of the Professional Quality of Life Scale (ProQOL Scale). This validated scale, created by Stamm (2010), measures the positive feelings helping professionals obtain from working with individuals who have experienced traumatic incidents in their lives. Each item contains five possible response choices ranging from "never" to "very often." Total scores potentially range from 10 to 50 , with scores of 22 or less designated as "low compassion satisfaction," scores of 23 to 41 designated as "average compassion satisfaction" 
and scores of 42 and above designated as "high compassion satisfaction." As this scale only applies to social workers working directly with clients, those who reported that they work only in "indirect practice" were not asked to answer this scale. For the current study, the Cronbach alpha for this instrument was 0.93 .

\section{Workplace Stress}

The questionnaire included the 8-item Workplace Stress Scale, designed and validated by the Marlin Company and the American Institute of Stress (2001).

Each item has five possible response choices ranging from "never" to "very often," with total scores ranging from 8 to 40. Five levels of workplace stress have been established: 8-15 (No Stress); 16-20 (Low); 21-25 (Moderate); 26-30 (Severe); and 31-40 (Profound) (Parmar et al. 2015). As this scale only applies to stress in organizational settings, participants who reported that they work exclusively in a private practice setting were not directed to complete this scale. For the current study, the Cronbach alpha for this scale was 0.83 .

\section{Workplace Environment Factors}

The eight items of this instrument, informed by the Expanded Nursing Stress Scale (French et al. 2000), asked participants their level of agreement regarding their work environment, including issues of training, supervision, work space, availability of technology, workplace safety, manageable caseload size, satisfaction with salary, and feeling valued as a professional. Response choices were scored as follows: (1) "strongly disagree;" (2) "somewhat disagree;" (3) "neither disagree or agree;" (4) "agree;" and (5) "strongly agree."

\section{Glad Chose Social Work}

An item in the survey inquired about participants' level of agreement with the statement: "I am glad I chose social work as my profession" with response choices ranging from (1) strongly disagree to (5) strongly agree.

\section{Valued as a Professional in Society}

This item asked respondents about their level of agreement with the statement: "I am valued as a professional in society" with response choices ranging from (1) strongly disagree to (5) strongly agree.

\section{Analysis}

In order to compare the results for demographic factors, wellness factors, practice factors, and fields of practice between participants age 60 and older with their younger counterparts, chi-square analysis was used for all variables except for "number of years of practice," for which a $t$ test was utilized. In order to compare the results of the two age cohorts for compassion satisfaction, workplace stress, the eight workplace environment issues, and the items regarding being "glad one chose social work" and feeling "valued as a professional in society," $t$ - tests were used. In addition, the bivariate results between the age cohorts for compassion satisfaction and workplace stress were stratified according to gender (male and female), race (White and non-White), sexual orientation (heterosexual and sexual minority), presence of mental health problems (yes and no), and presence of serious physical health problems (yes and no), with a $t$ - test conducted for the analysis of each group separately. A multivariate analysis utilizing linear regression was then performed to determine which demographic, wellness, and practice factors including being 60 years of age and older affected the participants' levels of compassion satisfaction and workplace stress, as well as their being "glad they chose social work as a profession" and feeling "valued as a professional in society."

\section{Results}

\section{Characteristics of the Total Sample}

The mean age of the participants was $45.5($ S.D. $=13.0)$, with a range of 21 to 86 . As noted previously, 870 (17.6\%) of the respondents were 60 years of age and older, and 4,076 $(82.4 \%)$ were under 60 years of age. The mean age of the older cohort was $64.9($ S.D. $=4.5)$, and the mean age of the younger cohort was $41.3($ S.D. $=10.1)$.

The first column of Table 1 indicates that $89 \%$ of the sample identified as female, $11 \%$ as male, with only $0.3 \%$ (13 participants) identifying their gender as non-binary. Eight-three percent of participants identified as White, $6 \%$ as Black/African American, $4 \%$ as Latino/Hispanic, $1 \%$ as Asian, and nearly $6 \%$ as being in the "Mixed" or "Other" category. Over $95 \%$ of respondents were born in the United States and nearly $91 \%$ identified as heterosexual. Over half the sample reported that they were Christian, and nearly twothirds of the sample indicated that they were married or had a domestic partner.

Over a quarter of the sample indicated currently having serious physical health problems, and nearly $29 \%$ indicated that they were experiencing mental health problems. In regard to the latter, a fifth of the sample reported taking psychotropic medications and over a sixth reported accessing outpatient mental health treatment in the past year. Only 
Table 1 Differences between older and younger social workers: demographic and wellness factors

\begin{tabular}{|c|c|c|c|c|c|}
\hline & $\begin{array}{l}\text { All SW } \\
\%^{\mathrm{b}} \\
n=4946\end{array}$ & $\begin{array}{l}\text { SW }(60+) \\
\%^{\mathrm{b}} \\
n=870\end{array}$ & $\begin{array}{l}\text { SW (21-59) } \\
\%^{\mathrm{b}} \\
n=4076\end{array}$ & $\chi^{2}(d f)$ & $p^{\mathrm{a}}$ \\
\hline \multicolumn{6}{|l|}{ Demographic factors } \\
\hline Gender & & & & $93.13(2)$ & .001 \\
\hline Female & 88.8 & 79.9 & 90.7 & & \\
\hline Male & 10.9 & 20.1 & 9.0 & & \\
\hline Non-binary & 0.3 & .0 & 0.3 & & \\
\hline Race & & & & $20.70(4)$ & .001 \\
\hline White & 83.3 & 87.4 & 82.4 & & \\
\hline Black/African American & 6.1 & 4.4 & 6.5 & & \\
\hline Latino/Hispanic & 4.0 & 3.0 & 4.2 & & \\
\hline Asian & 1.0 & .0 & 1.2 & & \\
\hline Mixed/other & 5.6 & 5.2 & 5.7 & & \\
\hline Born in U.S. & 95.4 & 96.5 & 95.1 & $3.18(1)$ & .08 \\
\hline Heterosexual & 90.7 & 92.0 & 90.4 & $2.29(1)$ & .13 \\
\hline Religion & & & & $97.16(6)$ & .001 \\
\hline Christian & & & 54.8 & 46.1 & 56.7 \\
\hline Spiritual, but not religious & 22.2 & 26.6 & 21.3 & & \\
\hline Agnostic/Atheist & 8.0 & 5.9 & 8.4 & & \\
\hline Jewish & 5.2 & 10.2 & 4.1 & & \\
\hline None & 4.0 & 2.8 & 4.2 & & \\
\hline Buddhist & 1.2 & 1.5 & 1.2 & & \\
\hline Other & 4.5 & 6.9 & 4.5 & & \\
\hline Marital status & & & & $276.72(4)$ & .001 \\
\hline Married/domestic partner & 63.7 & 60.4 & 64.4 & & \\
\hline Single & 17.5 & 6.3 & 19.9 & & \\
\hline Divorced/separated & 13.9 & 22.4 & 12.1 & & \\
\hline Widowed & 1.8 & 6.7 & 0.7 & & \\
\hline Other & 3.1 & 4.1 & 2.9 & & \\
\hline \multicolumn{6}{|l|}{ Wellness factors } \\
\hline Mental health problems (total) & 28.5 & 19.3 & 30.5 & $43.91(1)$ & .001 \\
\hline Physical health problems & 26.4 & 31.2 & 25.3 & $12.69(1)$ & .001 \\
\hline Psychotropic medication & 20.8 & 15.9 & 21.8 & $15.42(1)$ & .001 \\
\hline Outpatient MH treatment & 18.2 & 10.5 & 19.8 & $42.45(1)$ & .001 \\
\hline Anxiety & 18.2 & 8.5 & 20.2 & $66.38(1)$ & .001 \\
\hline Depression & 14.7 & 10.8 & 15.5 & $12.53(1)$ & .001 \\
\hline Current Tobacco use & 11.9 & 8.9 & 12.6 & $9.39(1)$ & .002 \\
\hline Substance misuse problems & 2.2 & 1.9 & 2.3 & $0.55(1)$ & .46 \\
\hline Physical health self-rating & & & $21.91(2)$ & .001 & \\
\hline Excellent/very good & 58.7 & 65.7 & 57.2 & & \\
\hline Good & 33.1 & 27.8 & 34.2 & & \\
\hline Fair/poor & 8.3 & 6.4 & 8.6 & & \\
\hline
\end{tabular}

Note statistical significance for this study is designated as $p \leq .05$

${ }^{a}$ Testing of statistical significance is between older social workers (Age 60 and Older) and social workers younger than 60

${ }^{b}$ Percentages do not include items not answered by participants a little over $2 \%$ of respondents reported current problems with alcohol and drugs, while $12 \%$ of the sample indicated that they currently use tobacco.
As seen in Table 2, over $80 \%$ of the sample reported that their highest degree was an MSW, over 39\% of respondents worked only in direct practice, over $21 \%$ worked only in 
Table 2 Differences between older and younger social workers: practice factors and fields of practice

\begin{tabular}{|c|c|c|c|c|c|}
\hline & $\begin{array}{l}\text { All SW } \\
\% \mathrm{~b} \\
n=4946\end{array}$ & $\begin{array}{l}\text { SW (60+) } \\
\% \mathrm{~b} \\
n=870\end{array}$ & $\begin{array}{l}\text { SW (21-59) } \\
\%^{\mathrm{b}} \\
n=4076\end{array}$ & $\chi^{2}(d f)$ & $p^{\mathrm{a}}$ \\
\hline \multicolumn{6}{|l|}{ Practice factors } \\
\hline Highest degree & & & & $55.45(2)$ & .001 \\
\hline MSW & 81.4 & 85.4 & 80.5 & & \\
\hline BSW & 17.0 & 10.8 & 18.3 & & \\
\hline Doctorate & 1.6 & 3.8 & 1.1 & & \\
\hline Area of practice & & & & $1.37(2)$ & .50 \\
\hline Direct practice only & 39.2 & 41.1 & 38.9 & & \\
\hline Direct/indirect practice & 39.1 & 37.7 & 39.4 & & \\
\hline Indirect practice only & 21.6 & 21.2 & 21.7 & & \\
\hline Private practice only & 12.2 & 30.3 & 8.3 & $323.66(1)$ & .001 \\
\hline \multicolumn{6}{|l|}{ Fields of practice ${ }^{c}$} \\
\hline Mental health & 61.9 & 70.2 & 60.1 & $31.14(1)$ & .001 \\
\hline Families/couples & 31.5 & 42.3 & 29.2 & $56.82(1)$ & .001 \\
\hline Aging/older adults & 31.4 & 34.9 & 30.6 & $6.23(1)$ & .01 \\
\hline Schools & 22.1 & 19.3 & 22.7 & $4.70(1)$ & .03 \\
\hline Housing/homelessness & 14.7 & 12.2 & 15.2 & $5.25(1)$ & .02 \\
\hline Military/veterans & 9.4 & 14.4 & 8.4 & $29.96(1)$ & .001 \\
\hline Employee assistance programs & 6.3 & 17.5 & 3.9 & $225.56(1)$ & .001 \\
\hline \multirow[t]{2}{*}{ Disaster response } & 3.7 & 7.5 & 2.9 & $42.82(1)$ & .001 \\
\hline & Mean (SD) & Mean (SD) & Mean (SD) & $t(d f)$ & $p$ \\
\hline No. years of practice & $15.9(11.2)$ & $29.0(11.1)$ & $13.2(9.1)$ & $43.79(4806)$ & .001 \\
\hline
\end{tabular}

Note statistical significance for this study is designated as $p \leq .05$

${ }^{a}$ Testing of statistical significance is between older (age 60 and older) and social workers younger than 60

${ }^{\mathrm{b}}$ Percentages do not include items not answered by participants

${ }^{c}$ Participants could choose as many fields of practice as apply to them. Only those eight that demonstrated statistically significant differences between the cohorts are included in this table indirect practice, with the remainder (39\%) performing both functions. An eighth of the sample worked exclusively in a private practice setting. Respondents' mean number of years practicing social work was 16 .

\section{Results of Bivariate Analysis}

\section{Demographic Factors}

As reflected in Table 1, the older social workers were far more likely to be male (20.1\% vs. $9.0 \%)$. Furthermore, whereas 13 respondents under age 60 identified as "other gender," none of the respondents who were 60 and older did so. The older respondents were more likely to identify as White $(87.4 \%$ vs. $82.4 \%)$ than the younger ones. In regard to religious preference, the older workers were more than twice as likely to identify as Jewish (10.2\% vs. $4.1 \%)$, less likely to identify as Christian ( $46.1 \%$ vs. $56.7 \%)$, more likely to identify as "spiritual but not religious" (26.6\% vs $21.3 \%)$, and less likely to report that they were atheist or agnostic (5.9\% vs. $8.4 \%)$. They were far less likely to report being "single" (6.3\% vs. 19.9\%), and far more likely to report being divorced/separated (22.4\% vs. $12.1 \%)$ and widowed (6.7\% vs. $0.7 \%)$.

\section{Wellness Factors}

Table 1 indicates that the older cohort was far less likely to report current mental health problems (19.3\% vs. $30.5 \%$ ) than the younger cohort, and experienced less depression (10.8\% vs. $15.5 \%)$ and far less anxiety ( $8.5 \%$ vs. $20.2 \%)$. These differences extended into the domain of treatment, in which the older workers were less likely to have taken psychotropic medication in the prior year $(15.9 \%$ vs. $21.8 \%)$ and far less likely to have utilized outpatient mental health treatment in the last year ( $10.5 \%$ vs. $19.8 \%)$. The older respondents were more apt to report current serious physical health problems $(31.2 \%$ vs. $25.3 \%$ ), but conversely rated their physical health as better than the younger respondents. For example, $65.7 \%$ of older participants rated their physical health as excellent or very good in comparison to $57.2 \%$ of the younger 
respondents and were less likely to report their physical health as fair or poor $(6.4 \%$ vs. $8.6 \%)$. The older cohort was also less likely to report current use of tobacco than the younger cohort ( $8.9 \%$ vs $12.6 \%$ ). There were no statistically significant differences in rates of current alcohol and drug problems between the groups.

\section{Practice Factors}

Table 2 shows extremely large differences between the older and younger social workers in regard to two variables: length of time practicing social work and being in private practice. Whereas the mean length of time practicing social work for the younger cohort was 13.2 years, it was 29.0 years for the older group. Nearly four times the number of older cohort respondents reported working exclusively in a private practice setting $(30.3 \%$ vs. $8.3 \%$ ). In addition, older social workers were more likely to have attained an MSW degree $(85.4 \%$ vs $80.5 \%)$ and a doctorate in social work (3.8\% vs. $1.1 \%)$ than the younger ones. There were no statistically significant differences between the groups in regard to working in direct or indirect practice.

\section{Fields of Practice}

Table 2 shows that there were significant employment differences between older and younger social workers in eight out of a list of 21 fields of practice. Only the fields of practice that demonstrated statistically significant differences between the age cohorts are shown in Table 2. The older workers were more likely to report having worked in mental health settings, with families and couples, with aging/older adults, with military personal/veterans, in disaster response, and in employee assistance programs. The difference in working for employee assistance programs was particularly striking (17.5\% vs. 3.9\%). The younger workers were more likely to have worked in schools and in the area of housing/ homelessness.

\section{Compassion Satisfaction}

Table 3 indicates that among participants working directly with clients, the older respondents had higher mean scores of compassion satisfaction than the younger respondents. Both groups scored within the range of "high compassion satisfaction," but with a mean of 44.7 , the older groups' scores were particularly high, considering that the maximum score is 50 .
Table 3 Differences between older and younger social workers: compassion satisfaction; workplace stress; workplace environment factors; glad chose social work; and valued as a professional in society

\begin{tabular}{|c|c|c|c|c|c|}
\hline & $\begin{array}{l}\text { All SW } \\
\text { Mean (S.D.) }\end{array}$ & $\begin{array}{l}\text { SW (60+) } \\
\text { Mean (S.D.) }\end{array}$ & $\begin{array}{l}\text { SW (21-59) } \\
\text { Mean (S.D.) }\end{array}$ & $t(d f)$ & $p^{\mathrm{a}}$ \\
\hline Compassion satisfaction $^{\mathrm{b}}:(\mathrm{N}=3597)$ & $42.4(6.2)$ & $44.7(5.5)$ & $42.0(6.3)$ & $9.87(3595)$ & .001 \\
\hline Workplace stress $^{\mathrm{c}}:(\mathrm{N}=4120)$ & $20.9(5.8)$ & $19.9(6.1)$ & $21.0(5.7)$ & $-4.39(4118)$ & .001 \\
\hline \multicolumn{6}{|l|}{ Workplace environment $^{\mathrm{d}}:(\mathrm{N}=4912)$} \\
\hline Access to technologies & $4.1(1.1)$ & $4.2(1.0)$ & $4.0(1.2)$ & $4.53(4900)$ & .001 \\
\hline Sufficient training & $4.1(1.0)$ & $4.4(0.9)$ & $4.0(1.0)$ & $10.09(4910)$ & .001 \\
\hline Safe from physical harm & $4.1(1.0)$ & $4.2(1.0)$ & $4.0(1.0)$ & $5.66(4818)$ & .001 \\
\hline Sufficient work space & $4.0(1.2)$ & $4.2(1.1)$ & $4.0(1.2)$ & $0.87(4865)$ & .001 \\
\hline Valued in workplace & $3.9(1.2)$ & $4.1(1.2)$ & $3.8(1.2)$ & $7.24(4845)$ & .001 \\
\hline Manageable caseload & $3.7(1.2)$ & $3.9(1.2)$ & $3.6(1.2)$ & $6.72(4521)$ & .001 \\
\hline Good supervision & $3.5(1.3)$ & $3.6(1.3)$ & $3.5(1.3)$ & $0.60(4561)$ & .55 \\
\hline Satisfied with income/salary & $3.1(1.4)$ & $3.4(1.4)$ & $3.1(1.4)$ & $6.52(4891)$ & .001 \\
\hline Glad chose social work ${ }^{\mathrm{e}}:(\mathrm{N}=4938)$ & $4.1(0.9)$ & $4.3(0.9)$ & $4.1(0.9)$ & $6.98(4936)$ & .001 \\
\hline $\begin{array}{l}\text { Valued as a professional in society } \mathrm{e}^{\mathrm{e}} \\
(\mathrm{N}=4939)\end{array}$ & $3.4(1.0)$ & $3.7(1.0)$ & $3.4(1.0)$ & $8.38(4937)$ & .001 \\
\hline
\end{tabular}

Note statistical significance for this study is designated as $p \leq .05$

${ }^{\text {a }}$ Testing of statistical significance is between older (age 60 and older) and social workers younger than 60

${ }^{\mathrm{b}}$ Compassion Satisfaction scores potentially range from 10 to 50 . As this scale only applies to social workers working in direct practice with clients, respondents working exclusively in indirect practice were not asked to complete this scale

${ }^{\mathrm{c}}$ Workplace Stress scores potentially range from 8 to 40 . As this scale applies only to workplace stress in organizational settings, respondents working exclusively in private practice were not asked to complete this scale

${ }^{\mathrm{d}}$ Workplace Environment, scores potentially range from 1 to 5 . The means do not include participants who chose "not applicable" (n/a) as a response choice

${ }^{\mathrm{e}}$ Glad Chose Social Work and Valued as a Professional in Society scores potentially range from 1 to 5 
Nearly four times as many of the older cohort reported working exclusively in a private practice setting as the younger respondents (30\% vs. $8.3 \%$ ). Therefore, an analysis of the differences in compassion satisfaction for those not working exclusively in private practice was performed in order to ensure that the variable of private practice was not confounding the relationship between age and compassion satisfaction. When comparing the 386 older respondents who were not working exclusively in private practice with their 2669 younger counterparts, the differences in compassion satisfaction remained statistically significant (means: 43.9 vs. $41.7 ; t=6.24, d f=3053, p=.001)$.

\section{Workplace Stress}

Table 3 demonstrates that for participants not working exclusively in private practice, the older respondents had lower mean scores of workplace stress than the younger respondents. With a mean score of 21.0 , the younger group fell in the low end of the range of "moderate stress," whereas with a mean score of 19.9, the older group fell in the range of "low stress."

\section{Workplace Environment Factors}

Table 3 illustrates that for seven out of the eight workplace environment factors, the older cohort had higher scores.
Only regarding "receiving good supervision," were there no statistically significant differences between the groups.

\section{Glad Chose Social Work}

Table 3 demonstrates that a greater percentage of social workers in the older group either strongly agreed or agreed with the statement, "I am glad I chose social work as my profession" than those in the younger group. More specifically, $88.5 \%$ of the older respondents in comparison with $82.1 \%$ of the younger respondents either "strongly agreed" or "agreed" with that statement, which represented a statistically significant difference.

\section{Valued as a Professional in Society}

Similarly, a greater percentage of respondents in the older cohort $(66.1 \%)$ either strongly agreed or agreed with the statement, "I am valued as a professional in society" than respondents in the younger cohort (55.0\%), a difference that was statistically significant.

\section{Stratified Results for Compassion Satisfaction and Workplace Stress}

Table 4 presents bivariate tests of the differences in compassion satisfaction and workplace stress between the older and younger respondents when the sample is stratified by

Table 4 Mean differences in compassion satisfaction and workplace stress by age group when stratified by demographic and wellness factors

\begin{tabular}{|c|c|c|c|c|c|c|c|c|c|c|}
\hline & \multicolumn{5}{|c|}{ Compassion satisfaction } & \multicolumn{5}{|c|}{ Workplace stress } \\
\hline & \multicolumn{5}{|c|}{ Means (SD) } & \multicolumn{5}{|c|}{ Means (SD) } \\
\hline & $n$ & SW (60+) & SW (21-59) & $t$ & $p^{\mathrm{a}}$ & $n$ & SW (60+) & SW (21-59) & $t$ & $p^{\mathrm{a}}$ \\
\hline \multicolumn{11}{|l|}{ Gender } \\
\hline Female & 3195 & $44.7(5.5)$ & $42.0(6.3)$ & 8.75 & .001 & 3684 & $20.1(6.0)$ & $21.1(5.7)$ & -3.27 & .001 \\
\hline Male & 379 & $44.6(5.3)$ & $41.9(6.4)$ & 4.20 & .001 & 413 & $19.1(6.3)$ & $21.0(5.9)$ & -2.70 & .005 \\
\hline \multicolumn{11}{|l|}{ Race } \\
\hline White & 3014 & $44.6(5.7)$ & $41.8(6.3)$ & 9.37 & .001 & 3398 & $19.8(6.0)$ & $21.1(5.6)$ & -4.41 & .001 \\
\hline Non-white & 583 & $45.4(4.0)$ & $42.9(6.1)$ & 3.56 & .001 & 722 & $20.0(6.6)$ & $20.8(6.2)$ & -.99 & .33 \\
\hline \multicolumn{11}{|l|}{ Sexual orientation } \\
\hline Heterosexual & 3241 & $44.7(5.5)$ & $42.0(6.3)$ & 9.45 & .001 & 3732 & $19.9(6.1)$ & $21.0(5.7)$ & -4.07 & .001 \\
\hline Sexual minority & 338 & $44.6(5.4)$ & $41.9(6.5)$ & 2.82 & .005 & 369 & $19.7(5.7)$ & $21.3(6.2)$ & -1.50 & .14 \\
\hline \multicolumn{11}{|c|}{ Mental health problems } \\
\hline Yes & 1066 & $43.2(6.3)$ & $40.0(6.9)$ & 4.89 & .001 & 1215 & $22.4(6.3)$ & $23.3(6.0)$ & -1.45 & .15 \\
\hline No & 2519 & $45.0(5.2)$ & $42.9(5.8)$ & 7.52 & .001 & 2889 & $19.1(5.8)$ & $20.0(5.3)$ & -3.10 & .002 \\
\hline \multicolumn{11}{|c|}{ Physical health problems } \\
\hline Yes & 978 & $44.2(5.9)$ & $41.0(6.8)$ & 6.13 & .001 & 1079 & $21.5(6.0)$ & $23.0(6.2)$ & -3.14 & .002 \\
\hline No & 2615 & $44.9(5.3)$ & $42.3(6.1)$ & 8.03 & .001 & 3034 & $19.1(6.0)$ & $20.3(5.4)$ & -4.17 & .001 \\
\hline
\end{tabular}

Note statistical significance for this study is designated as $p \leq .05$

${ }^{\text {a }}$ Testing of statistical significance is between older (age 60 and older) and social workers younger than 60 
demographic factors (gender; race; sexual orientation) and wellness factors (presence and absence of mental health problems; presence and absence of serious physical health problems). The older workers consistently reported higher levels of compassion satisfaction than the younger workers for every demographic and wellness factor. However, while the non-stratified analysis indicated that younger social workers experienced more workplace stress than their older counterparts, stratified analyses suggest that these age differences may not hold for some subsamples examined. Specifically, while younger White social workers reported higher workplace stress levels than their older counterparts, there was no significant difference between older and younger non-White social workers for this variable. Similarly, although the age difference in workplace stress was statistically significant among respondents who identified as heterosexual, this was not the case for those who identified as a sexual minority. However, this could have been due to the small sample of sexual minorities, particularly for the older social worker group. In addition, among those with current mental health problems, there was no difference in workplace stress between the older and younger groups. However, among those with no current mental health problems, the younger group reported higher workplace stress. Table 4 also indicates that older participants reported statistically significant lower levels of workplace stress than the younger participants among males, females, those who reported serious physical health problems, and those who did not report serious physical health problems.

\section{Results of Multivariate Analysis}

Table 5 indicates that in the linear regression analysis, being age 60 and older remained significantly associated with higher levels of compassion satisfaction, being glad one chose social work, and feeling valued as a professional in society. However, the association between being age 60 and older and lower levels of workplace stress did not reach statistical significance as it did in the bivariate analysis.

The factor that was most associated with increased workplace stress and decreased levels of the other three variables was the presence of mental health problems, although physical health problems also had a statistically significant correlation with these variables. Self-identifying as Black/ African American or Latino/Hispanic was associated with higher levels of compassion satisfaction and being Black/ African American was associated with lower levels of workplace stress. Being born in the United States was correlated with less compassion satisfaction. In comparison to being married, being single and divorced/separated was associated with greater workplace stress and identifying as agnostic/atheist was associated with lower levels of compassion satisfaction, being glad one chose social work, and feeling valued in society as a professional. Identifying as Jewish was negatively correlated with being glad one chose social work and feeling valued in society as a professional, and identifying as "spiritual, but not religious" was negatively correlated with feeling valued in society as a professional. The number of years practicing as a social worker was positively associated with compassion satisfaction and feeling valued as a professional in society. Engaging solely in indirect practice positively correlated with lower levels of workplace stress and working exclusively in private practice was positively correlated with higher levels of compassion satisfaction. These two variables were also positively associated with being glad one chose social work and feeling valued as a professional in society. Participants reporting that their work involved both direct practice with clients as well as indirect practice was associated with higher levels of compassion satisfaction in their work.

\section{Discussion}

This exploratory cross-sectional study revealed statistically significant differences between younger (21-59) and older (ages 60-86) employed social workers for many of the variables that were examined. When interpreted in the context of a productive aging framework, a striking feature of the results is the positive nature of the findings for the older workers in comparison to their younger counterparts. In a bivariate analysis, the older social workers reported statistically significant higher levels of compassion satisfaction, lower levels of workplace stress, greater feelings of being valued as a professional in society, and greater likelihood of being glad they chose social work as a profession. Except for workplace stress, these differences were also statistically significant in a multivariate analysis. When stratifying the bivariate results according to gender, race, sexual orientation, presence of mental health problems, and presence of serious physical health problems, the older social workers had statistically significant higher levels of compassion satisfaction in every group. Furthermore, although nearly a third of the younger social workers reported mental health problems, this was the case for less than a fifth of the social workers who were 60 years old and older. The older workers also reported more positive perceptions of their work environment for seven out of the eight issues measured. According to a life-span perspective, the aging process is seen as multidirectional, involving both losses and gains (CDC 2011). In this regard, the social workers over age 60 reported higher rates of serious physical health problems, as would be expected. However, the resilience of this group is exemplified by the finding that despite reporting more serious physical health problems, they rated their physical health condition more positively than the younger group. 
Table 5 Demographic, wellness, and practice factors' effect on compassion satisfaction, workplace stress, glad chose social work and valued as a professional in society

\begin{tabular}{|c|c|c|c|c|c|c|c|c|}
\hline & \multirow{2}{*}{\multicolumn{2}{|c|}{$\begin{array}{l}\text { Compassion } \\
\text { satisfaction }\end{array}$}} & \multirow{2}{*}{\multicolumn{2}{|c|}{$\begin{array}{l}\text { Workplace stress } \\
\overline{N=4120}\end{array}$}} & \multirow{2}{*}{\multicolumn{2}{|c|}{$\begin{array}{l}\text { Glad chose social } \\
\text { work } \\
\mathrm{N}=4938\end{array}$}} & \multirow{2}{*}{\multicolumn{2}{|c|}{$\begin{array}{l}\begin{array}{l}\text { Valued as a } \\
\text { professional }\end{array} \\
\mathrm{N}=4939\end{array}$}} \\
\hline & & & & & & & & \\
\hline & $\beta$ & $p$ & $\beta$ & $p$ & $\beta$ & $p$ & $\beta$ & $p$ \\
\hline \multicolumn{9}{|l|}{ Gender $^{\mathrm{a}}$} \\
\hline Male & -.02 & .23 & -.01 & .50 & -.02 & .25 & .00 & .81 \\
\hline Other & .00 & .90 & -.02 & .26 & .00 & .91 & .01 & .46 \\
\hline \multicolumn{9}{|l|}{ Race $^{\mathrm{b}}$} \\
\hline Black/Afr. Amer & .06 & .001 & -.05 & .002 & .00 & .91 & .02 & .22 \\
\hline Latino/Hispanic & .04 & .02 & -.01 & .46 & -.01 & .73 & .00 & .83 \\
\hline Asian & -.01 & .52 & .00 & .91 & -.01 & .39 & .01 & .63 \\
\hline Mixed/other & .02 & .29 & .02 & .30 & .01 & .66 & -.01 & .70 \\
\hline Born in U.S & -.04 & .04 & .01 & .68 & .02 & .15 & .00 & .88 \\
\hline Heterosexual & -.02 & .21 & .03 & .11 & -.01 & .48 & -.02 & .34 \\
\hline \multicolumn{9}{|l|}{ Religion $^{c}$} \\
\hline Jewish & .00 & .86 & -.02 & .23 & -.04 & .02 & -.04 & .01 \\
\hline Buddhist & .03 & .09 & .01 & .39 & .01 & .72 & -.02 & .33 \\
\hline Spiritual, not Religious & .03 & .16 & .02 & .31 & .01 & .76 & -.05 & .002 \\
\hline Agnostic/atheist & -.06 & .001 & .01 & .68 & -.04 & .01 & -.08 & .001 \\
\hline Other & -.02 & .23 & .01 & .55 & -.01 & .55 & -.01 & .42 \\
\hline \multicolumn{9}{|l|}{ Marital status $^{\mathrm{d}}$} \\
\hline Single & -.02 & .24 & .04 & .03 & -.01 & .42 & -.02 & .18 \\
\hline Divorced/sep & -.03 & .06 & .06 & .001 & -.02 & .17 & .00 & .96 \\
\hline Widowed & -.01 & .60 & -.01 & .38 & .01 & .41 & .02 & .11 \\
\hline Other & .02 & .19 & .03 & .04 & .02 & .26 & -.01 & .39 \\
\hline Mental health problems & -.17 & .001 & .21 & .001 & -.09 & .001 & -.09 & .001 \\
\hline Substance misuse problems & -.02 & .21 & .02 & .22 & -.02 & .13 & -.03 & .09 \\
\hline Physical health problems & -.05 & .004 & .15 & .001 & -.04 & .01 & -.04 & .004 \\
\hline \multicolumn{9}{|l|}{ Highest degree $^{\mathrm{e}}$} \\
\hline MSW & .03 & .09 & .00 & .93 & .02 & .24 & -.01 & .75 \\
\hline Doc & .02 & .40 & -.02 & .37 & .01 & .60 & .01 & .62 \\
\hline \multicolumn{9}{|l|}{ Area of practice ${ }^{f}$} \\
\hline Indirect & - & - & -.06 & .001 & .07 & .001 & .06 & .001 \\
\hline Dir/indirect & .09 & .001 & -.01 & .69 & .07 & .001 & .03 & .06 \\
\hline Years of practice & .09 & .001 & -.02 & .22 & .00 & .95 & .06 & .002 \\
\hline Only private practice & .11 & .001 & - & - & -.06 & .001 & .10 & .001 \\
\hline Age 60 and older & .07 & .001 & -.03 & .07 & .08 & .001 & .05 & .007 \\
\hline $\mathrm{R}^{2}$ & .115 & & .105 & & .038 & & .053 & \\
\hline $\mathrm{F}$ & $16.8 *$ & & $16.6^{*}$ & & $6.4 *$ & & $9.1^{*}$ & \\
\hline
\end{tabular}

Note statistical significance for this study is designated as $p \leq .05$

${ }^{*} \mathrm{~F}$ is statistically significant at $p \leq .05$ level

${ }^{\mathrm{a}}$ Reference $=$ Female

${ }^{\mathrm{b}}$ Reference $=$ White

${ }^{\mathrm{c}}$ Reference $=$ Christian

${ }^{\mathrm{d}}$ Reference $=$ Married

${ }^{\mathrm{e}}$ Reference $=\mathrm{BSW}$

${ }^{\mathrm{f}}$ Reference $=$ Direct practice
The issue of survivorship bias is important to consider in this study. The licensed social workers in this study who were 60 years of age and older represent a group who chose to remain in the profession over the years. Social workers who experienced lower compassion satisfaction, more workplace stress, more negative feelings about the profession, 
and/or encountered significant bio-psychosocial difficulties were probably more likely to have left the social work profession before age 60 . This study did not explore the reasons social workers remain in or leave the profession as they become older, and this is certainly an area to explore in future research.

In regard to demographic differences, it is not surprising that the percentage of White social workers among the older groups was greater than that of the younger group. In 1970, the Council on Social Work Education (CSWE 1970) published Ethnic Minorities in Social Work Education, a book dedicated to strategies to enhance the number of non-White students graduating from social work programs. Indicating at least some success with this goal, a recent report of graduating social work students sponsored by CSWE indicated that far more non-White students are graduating from social work schools than in previous years (Salsberg et al. 2017). Differences in religious beliefs among the age groups are worth noting. The finding that a smaller percentage of the older group reported being atheist or agnostic conforms to general population trends, as studies indicate that older people around the world tend to believe more in God than younger people (Bryner 2012; Harms 2012). However, the reasons for a greater percentage of older respondents identifying as Jewish and "spiritual, but not religious," and the reason for a larger percentage of the younger group identifying as Christian is not clear and needs to be further explored. Although it is not surprising that the older social workers were less likely to report being single and more likely to be widowed or divorced/separated, it is indeed unexpected that over twice as many older social workers were male than younger social workers. As there has been no reported decrease in male social workers entering the field over the years, this seems to indicate that male social workers are more likely to remain working in the field beyond age 60 than their female counterparts. This is another area that needs further exploration. Although only 13 participants identified their gender as non-binary, it is noteworthy that none of them reported being 60 years or older. This probably reflects changing mores regarding issues of gender identity among younger participants.

Despite the numerous statistically significant differences between the social workers 60 years and older and the younger social workers, it is important to note that there were many commonalities between them. While the older social workers were more likely to be male and White, both cohorts were overwhelmingly female and White, reflecting the demographics of U.S. licensed social workers (Whitaker et al. 2006). Furthermore, over $90 \%$ of both cohorts identified as heterosexual. In both groups, the prevalence of mental health problems was far higher than substance misuse problems, the latter which was less than $3 \%$ in both cohorts, a figure that is lower than in the population at large.
It is possible that the stigma regarding admitting a substance use problem may have minimized the respondents' desire to reveal this on a survey. However, it is also possible that social workers may deny such problems or that they may not have remained in the workforce if their substance use problems became severe. It is worth noting that less than $9 \%$ of the participants in both groups rated their physical health as fair or poor and that the proportions working in direct practice, indirect practice, or a combination of both were very similar. Finally, it is important to note that both the older and younger participants attained mean scores in the high range of compassion satisfaction and that over $80 \%$ of both groups indicated that they were glad they chose social work as a profession. With so many commonalities between the older and younger social workers, it is of utmost importance that social service agencies find ways to capitalize on the strengths of social workers from all age groups in order to have an effective multigenerational workforce. Future studies should focus on the specific strengths of different age groups in the social work profession and how they can be utilized together to enhance agency functioning.

In addition to exploring the differences between the older social workers and younger participants, the multivariate analysis demonstrated that numerous other factors affected compassion satisfaction, workplace stress, feeling glad one chose social work as a career, and feeling valued as a professional in society. Although an in-depth discussion of these results is beyond the scope of this article, it is important to emphasize that respondents reporting they experienced mental health problems was the factor that was most robustly associated with lower compassion satisfaction and greater workplace stress. This would seem to indicate that agencies need to provide more support for social workers who are encountering such difficulties, both for humane reasons and for the possible impact of workers' mental health problems on the quality of their work. This is particularly important as $28.5 \%$ of the sample reported the presence of mental health problems. The findings that being Black/African American or Latino/Hispanic was associated with higher levels of compassion satisfaction, and that being Black/African American was associated with lower levels of workplace stress are important and need to be further explored.

\section{Implications of Study}

This study found that licensed social workers 60 years of age and older who remained employed in the field represented nearly $18 \%$ of respondents $(n=870)$ and scored higher than their younger counterparts in compassion satisfaction. They also perceived their work environments and the social work profession more favorably. Although there have been a lack of studies correlating compassion satisfaction with working alliance or therapeutic 
outcomes, numerous studies have found that compassion satisfaction is inversely correlated with secondary traumatic stress, compassion fatigue and burnout among helping professionals working with clients affected by traumatic issues (e.g. Collins and Long 2003; Harr et al. 2014; Pelon 2017). Furthermore, a study of social workers by Wagaman et al. (2015) and a large study of physicians (Gleichgerrcht and Decety 2013) found that compassion satisfaction was positively correlated with the ability to empathize, indicating that older social workers may be a very valuable resource in working with clients in general, as well as in being able to handle the difficulties of working with clients in traumatic situations. It is recommended that future studies examine the effect of social workers' age on effectiveness with treatment outcomes and on their ability to form a positive therapeutic alliance, as this study did not do so.

The findings from this study conform to previous studies that have found that older workers tend to have greater work satisfaction than younger groups (Besen et al. 2013). However, the workplace environment factors explored in this study (e.g. sufficient training, safe from physical harm, manageable caseload, etc.) were very different from the work characteristics explored in the literature on work satisfaction such as job autonomy, friendship, skill variety, etc. (Zacher and Schmitt 2016). Future studies of the effects of age on the job satisfaction of the social work workforce could more specifically focus on these latter factors.

\section{Limitations}

There are a number of important limitations to the findings of this study. First of all, although reflecting the different regions of the country and demographically similar to findings of a national random survey of U.S. licensed social workers published in 2006 (Whitaker et al. 2006), the data for this study are based on respondents who were licensed in an availability sample of only 13 states. Furthermore, the response rate was only $28 \%$. This raises the issue of the generalizability of the findings to the greater social work population. Second, in this cross-sectional study, it is not possible to determine the impact of cohort and period effects when examining the differences found between the older and younger respondents. Third, the data may reflect response bias since some participants may not have responded truthfully to stigmatizing personal questions such as those focusing on their mental health and substance misuse. Last, given the lack of literature on the topics discussed, it is difficult to compare the findings of this study to any other research on the growing population of older social workers.

\section{Conclusion}

According to the World Health Organization (WHO 2018), the global population of people aged 60 years and older is expected to more than double by 2050 . Among the aging population in the United States are licensed social workers, many of whom will remain in the workforce as they become older. The results of this study demonstrate that social workers who remain in the profession after age 60 have higher levels of compassion satisfaction and more positive attitudes towards both having chosen social work as a profession and their current work environments than their younger counterparts. However, given the lack of literature on aging social workers, more research is greatly needed. Studies should explore the differences in characteristics between the older social workers who remain in the workforce compared to those who are no longer employed, whether by choice or necessity. Studies are also needed regarding what workplace factors or changes in the work environment would allow for more social workers to continue in their productive work roles as they age. To make full use of a productive aging workforce, much more research about social workers and their workplaces needs to be performed in the future.

Acknowledgement The authors wish to acknowledge Dr. Jeffrey Steen for his contribution to the original study and to thank Andrew Han and Julia R. Gertopsky for their assistance with the literature search.

Funding The funding for this study was provided to Dr. Straussner by the Office for Research at the New York University Silver School of Social Work.

\section{References}

Bass, S. A., \& Caro, F. G. (2001). Productive aging: A conceptual framework. In N. Morrow-Howell, J. Hinterlong, \& M. Sherraden (Eds.), Productive aging (pp. 37-78). Baltimore, MD: John Hopkins University Press.

Berkman, L., Boersch-Supran, A., \& Avendano, M. (2015). Labor-force participation, policies \& practices in an aging America: Adaptation essential for a healthy and resilient population. Daedalus, 144(2), 41-54. https://doi.org/10.1162/DAED_a_00329.

Besen, E., Matz-Costa, C., Brown, M., Smyer, M. A., \& Pitt-Catsouphes, M. (2013). Job characteristics, core self-evaluations, and job satisfaction: What's age got to do with it? International Journal of Aging and Human Development, 76(4), 269-295. https ://doi.org/10.2190/AG.76.4.a.

Bouville, G., Dello Russo, S., \& Truxillo, D. (2018). The moderating role of age in the job characteristics-absenteeism relationship: A matter of occupational context? Journal of Occupational and Organizational Psychology, 91(1), 57-83. https://doi.org/10.1111/ joop.12188.

Bride, B. E. (2007). Prevalence of secondary traumatic stress among social workers. Social Work, 52(1), 63-70. https://doi. org/10.1093/sw/52.1.63. 
Bryner, J. (2012). Older people hold stronger belief in God. LiveScience. Retrieved March 29, 2019, from https://www.livescienc e.com/19971-belief-god-atheism-age.html.

Butler, R. N. (2010). Productive Aging. In R. C. Tallis (Ed.), Brocklehursts textbook of geriatric medicine and gerontology, New York: Springer (pp. 193-197). doi: https://doi.org/10.1016/b9781-4160-6231-8.10032-7h

Butler, R. N., \& Gleason, H. P. (1985). Productive aging: Enhancing vitality in later life. New York, NY: Springer.

Caringi, J. C., Hardiman, E. R., Weldon, P., Fletcher, S., Devlin, M., \& Stanick, C. (2017). Secondary traumatic stress and licensed clinical social workers. Traumatology, 23(2), 186-195. https:// doi.org/10.1037/trm0000061.

Centers for Disease Control and Prevention (CDC). (2011). What is productive aging? Retrieved August 10, 2019, from https://www. cdc.gov/niosh/topics/productiveaging/productiveaging.html.

Collins, S., \& Long, A. (2003). Too tired to care? The psychological effects of working with trauma. Journal of Psychiatric and Mental Health Nursing, 10(1), 17-27. https://doi.org/10.104 6/j.1365-2850.2003.00526.x.

Council on Social Work Education (CSWE) (1970). Ethnic minorities in social work education. New York, NY: Author.

Craig, C. D., \& Sprang, G. (2010). Compassion satisfaction, compassion fatigue, and burnout in a national sample of trauma treatment therapists. Anxiety, Stress, and Coping, 23(3), 319-339. https:// doi.org/10.1080/10615800903085818.

French, S. E., Lenton, R., Walters, V., \& Eyles, J. (2000). An empirical evaluation of an expanded Nursing Stress Scale. Journal of Nursing Measurement, 8(2), 161-178. https://doi. org/10.1891/1061-3749.8.2.161.

Gleichgerrcht, E., \& Decety, J. (2013). Empathy in clinical practice: How individual dispositions, gender, and experience moderate empathic concern, burnout, and emotional stress in physicians. PLOS ONE, 8(4), 1-12. https://doi.org/10.1371/journ al.pone.0061526.

Gonzales, E., Matz-Costa, C., \& Morrow-Howell, N. (2015). Increasing opportunities for the productive engagement of older adults: A response to population aging. The Gerontologist, 55(2), 252-261. https://doi.org/10.1093/geront/gnu176.

Harms, W. (2012). Belief in God rises with age, even in atheist nations. Chicago, Il: Uchicago news; University of Chicago Office of Communications. Retrieved March 23, 2019, from https://news.uchic ago.edu/story/belief-god-rises-age-even-atheist-nations.

Harr, C. R., Brice, T. S., Riley, K., \& Moore, B. (2014). The impact of compassion fatigue and compassion satisfaction on social work students. Journal for the Society for Social Work and Research, 5(2), 233-251. https://doi.org/10.1086/676518.

Hinterlong, J., Morrow-Howell, N., \& Sherraden, M. (2001). Productive aging: Principles and perspectives. In N. Morrow-Howell, J. Hinterlong, \& M. Sherraden (Eds.), Productive aging (pp. 3-18). Baltimore, MD: John Hopkins University Press.

Hochwarter, W. A., Ferris, G. R., Perrewé, P. L., Witt, L. A., \& Kiewitz, C. (2001). A note on the nonlinearity of the age-job-satisfaction relationship. Journal of Applied Social Psychology, 31(6), 1223-1237. https://doi.org/10.1111/j.1559-1816.2001.tb02671.x.

Howard, A. R. H., Parris, S., Hall, J. S., Call, C. D., Razuri, E. B., Purvis, K. B., et al. (2015). An examination of the relationships between professional quality of life, adverse childhood experiences, resilience, and work environment in a sample of human service providers. Children and Youth Services Review, 57, 141-148. https://doi.org/10.1016/j.childyouth.2015.08.003.

Hsu, H.-C. (2019). Age differences in work stress, exhaustion, wellbeing, and related factors from an ecological perspective. International Journal of Environmental Research and Public Health, 16(1), 50. https://doi.org/10.3390/ijerph16010050.
Johnson, S., Cooper, C., Cartwright, S., Donald, I., Taylor, P., \& Millet, C. (2005). The experience of work-related stress across occupations. Journal of Managerial Psychology, 20(2), 178-187. https ://doi.org/10.1108/02683940510579803.

Kaye, L. W., Butler, S. S., \& Webster, N. M. (2003). Toward a productive ageing paradigm for geriatric practice. Ageing International, 28(2), 200-213. https://doi.org/10.1007/s12126-003-1024-6.

Kelly, L., Runge, J., \& Spencer, C. (2015). Predictors of compassion fatigue and compassion satisfaction in acute care nurses. Journal of Nursing Scholarship, 47(6), 522-528. https://doi.org/10.1111/ jnu.12162.

Kulkarni, S., Bell, H., Hartman, J. L., \& Herman-Smith, R. L. (2013). Exploring individual and organizational factors contributing to compassion satisfaction, secondary traumatic stress, and burnout in domestic violence service providers. Journal of the Society for Social Work and Research, 4(2), 114-130. https://doi.org/10.5243/ jsswr.2013.8.

Lawson, G., \& Myers, J. E. (2011). Wellness, professional quality of life, and career-sustaining behaviors: What keeps us well? Journal of Counseling and Development, 89(2), 163-171. https://doi. org/10.1002/j.1556-6678.2011.tb00074.x.

Ng, T. W. H., \& Feldman, D. C. (2010). The relationships of age with job attitudes: A meta-analysis. Personnel Psychology, 63(3), 677718. https://doi.org/10.1111/j.1744-6570.2010.01184.x.

Parmar, K., Solanski, C., Parikh, M., \& Vankar, G. K. (2015). Gender differences in stress at workplace among doctors and nurses. GCSMC Journal of Medical Science, 4(2), 108-113.

Pelon, S. B. (2017). Compassion fatigue and compassion satisfaction in hospice social work. Journal of Social Work in End-of-Life and Palliative Care, 13(2-3), 134-150. https://doi.org/10.1080/15524 256.2017.1314232.

Sacco, T. L., Ciurzynski, S. M., Harvey, M. E., \& Ingersoll, G. L. (2015). Compassion satisfaction and compassion fatigue among critical care nurses. Critical Care Nurse, 35(4), 32-42. https://doi. org/10.4037/ccn2015392.

Salsberg, E., Quigley, L., Mehfoud, N., Acquviva, K., Wyche, K., \& Sliwa, S. (2017). Profile of the social work workforce. Washington, DC: The George Washington University Health Workforce Institute.

Schwartz, R. H., Tiamiyu, M. F., \& Dwyer, D. J. (2007). Social worker hope and perceived burnout. Administration in Social Work, 39(4), 103-119. https://doi.org/10.1300/J147v31n04_08.

Senreich, E., Straussner, S. L. A., \& Steen, J. (2019). The work experiences of social workers: Factors impacting compassion satisfaction and workplace stress. Journal of Social Service Research. https://doi.org/10.1080/01488376.2018.1528491.

Stamm, B. H. (2010). The concise ProQOL manual (2nd ed.). Pocatello, ID: ProQOL.org.

Steel, C., Macdonald, J., Schröder, T., \& Mellor-Clark, J. (2015). Exhausted but not cynical: Burnout in therapists working within Improving Access to Psychological Therapy Services. Journal of Mental Health, 24(1), 33-37. https://doi.org/10.3109/09638 237.2014.971145.

Straussner, S. L. A., Senreich, E., \& Steen, J. (2018). Wounded healers: A multistat study of licensed social workers' behavioral health problems. Social Work, 63(2), 125-133. https://doi.org/10.1093/ sw/swy012.

The Marlin Company \& The American Institute of Stress. (2001). The workplace stress scale. North Haven, CT: Authors.

Wagaman, M. A., Geiger, J. M., Shockley, C., \& Segal, E. A. (2015). The role of empathy in burnout, compassion satisfaction, and secondary traumatic stress among social workers. Social Work, 60(3), 201-209. https://doi.org/10.1093/sw/swv014.

Whitaker, T., Weismiller, T., \& Clark, E. (2006). Assuring the sufficiency of a frontline workforce: A national study of licensed social 
workers. Executive summary. Washington, D.C: National association of Social Workers.

World Health Organization (WHO). (2018). Ageing and health. Retrieved November 15, 2019, from https://www.who.int/newsroom/fact-sheets/detail/ageing-and-health.

Zacher, H., \& Schmitt, A. (2016). Work characteristics and occupational well-being: The role of age. Frontiers in Psychology. https ://doi.org/10.3389/fpsyg.2016.01411.
Publisher's Note Springer Nature remains neutral with regard to jurisdictional claims in published maps and institutional affiliations. 